\title{
Trial Sets Parameter Code
}

National Cancer Institute

\section{Source}

National Cancer Institute. Trial Sets Parameter Code. NCI Thesaurus. Code C117464.

A character or string that represents the short code name of the trial set parameter. 